\title{
Sensory w robotyzacji spawania
}

\section{Sensors in robotic welding}

\section{Streszczenie}

W artykule opisano sensory stosowane w aplikacjach zrobotyzowanych systemów spawalniczych oraz ich zalety i wady wpływające na dobór odpowiednich rozwiązań do poszczególnych zastosowań, umożliwiający osiągnięcie oczekiwanej jakości złączy oraz wymaganej wydajności procesu.

\section{Abstract}

The article presents the sensors used in the robotic applications for welding processes and their advantages and disadvantages to have an effect on selection of appropriate solutions for specific applications for achieving the desired quality of joints and welding process capacity.

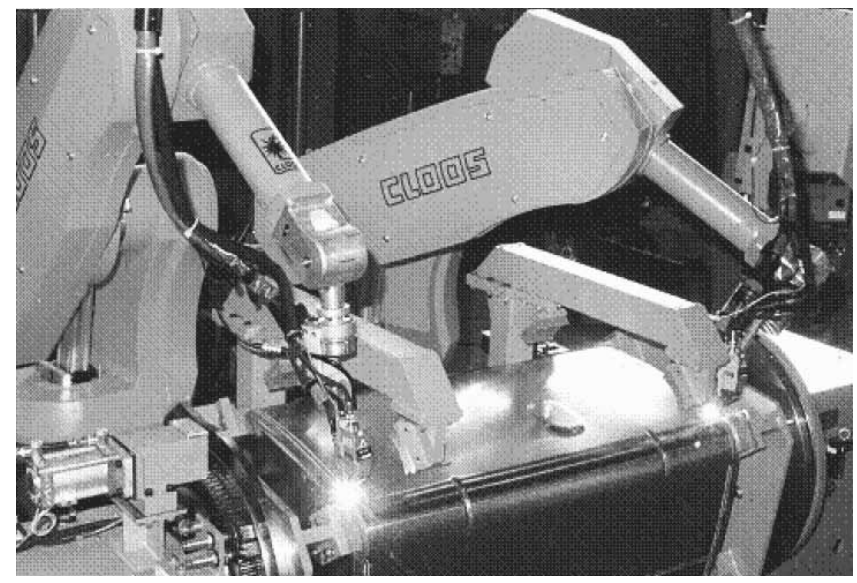

Rys. 1. Robot spawalniczy

Fig. 1. Robot for welding applications

do których wykorzystuje się specjalne roboty antywybuchowe. Kolejnym dużym obszarem wykorzystania robotów jest spawanie i cięcie materiałów (rys. 1).

We wszystkich aplikacjach stosuje się sensory w celu wyrównania skutków tolerancji wykonawczych.

\section{Sensory taktylne}

Sensory taktylne służą przeważnie do pomiaru rowka spawalniczego lub położenia części w trybie off-line. Zostaje rozpoznane rzeczywiste położenie części, które po przeliczeniu jest przenoszone do programu użytkowego. Pomiar może być wykonany za pomocą dyszy gazowej uchwytu spawalniczego, drutu spawalniczego lub za pomocą specjalnego sztyftu umieszczonego w pobliżu uchwytu 


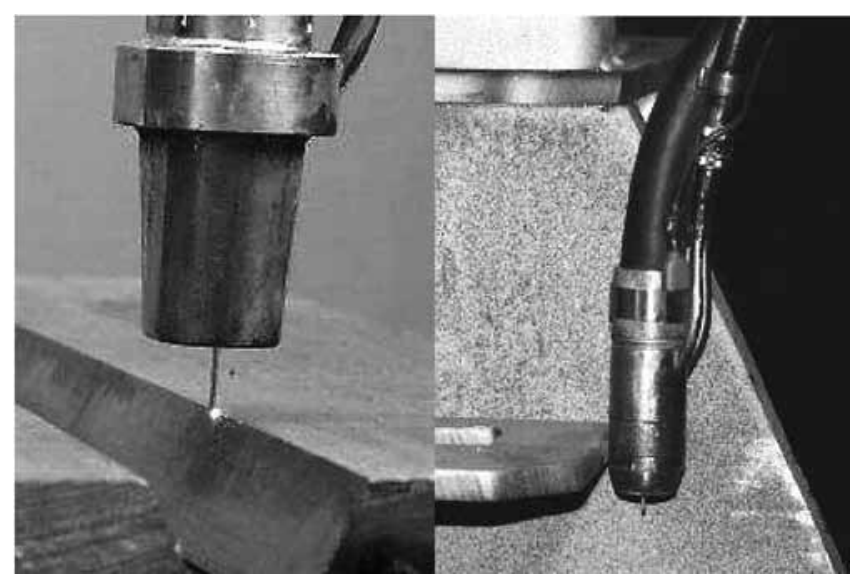

Rys. 2. Sensor taktylny do pomiaru off-line

Fig. 2. Tactile sensor for off-line measurements

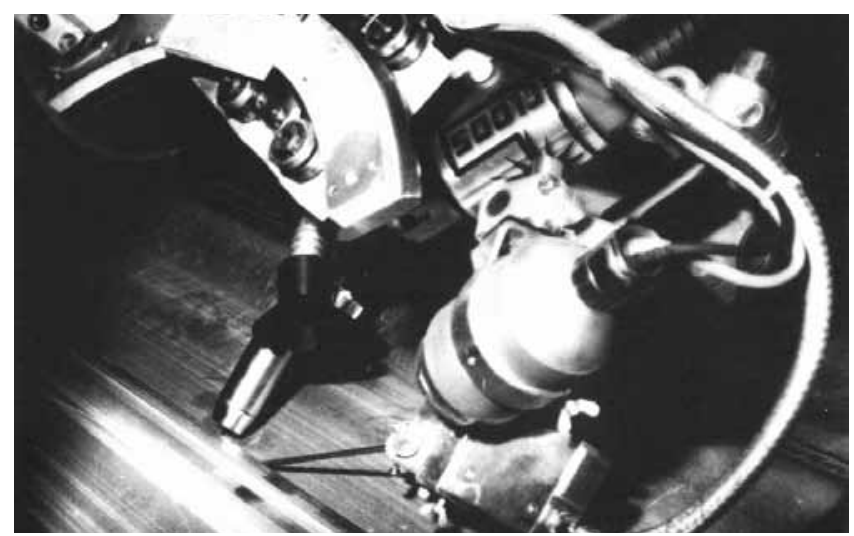

Rys. 3. Sensor analogowy

Fig. 3. Analog sensor

spawalniczego (rys. 2). Na element dotykowy zostaje podane napięcie $\mathrm{i}$ element ten podjeżdża $\mathrm{z}$ zadaną prędkością na obiekt pomiaru. Podczas zetknięcia ze spawanym podzespołem zostaje wytworzony sygnał i miejsce styku jest zapamiętane. Na podstawie zapamiętanego położenia oryginalnej części, dla której opracowano program, oraz na podstawie rzeczywistego położenia określonego sensorem, zostaje wyliczona różnica w położeniu trajektorii spoiny i opracowany wcześniej program wzorcowy przesuwa się o wektor wynikający z obliczeń. Wykonując pomiary w kilku punktach można tę metodę wykorzystać do przenoszenia programu w systemie transformacji 3D.

Do pomiarów on-line w rowku spawalniczym często stosuje się w konwencjonalnych urządzeniach sensor z sygnałem analogowym - sztyft lub igłę, które montowane są elastycznie przed uchwytem spawalniczym (rys. 3). Podczas procesu spawania rowek spawalniczy śledzony jest na bieżąco za pomocą sztyftu i położenie uchwytu spawalniczego jest korygowane w stosunku do zaprogramowanego toru. Ponieważ przebieg sensora w rowku nie jest sterowany, nie ma pewności, że prowadzenie uchwytu spawalniczego będzie poprawne przy przechodzeniu przez spoiny sczepne i na zakończeniu spoiny.

\section{Sensory łukowe}

Często stosuje się kombinacje $z$ sensorem taktylnym i sensorem łukowym.

Po wcześniejszym pozycjonowaniu uchwytu spawalniczego na początku spoiny za pomocą sensora taktylnego nadzór nad śledzeniem przebiegu spawania wzdłuż rowka przejmuje sensor łukowy zwany również sensorem prądowym. Sensor łukowy wymaga zastosowania zakosowego ruchu uchwytu spawalniczego poprzecznego w stosunku do kierunku spawania (rys. 4). W prawym i lewym położeniu zostaja przy każdym zakosie sprawdzone przebiegi prądu i napięcia. Sygnały prądowe i napięciowe są przeliczane przez system sterowania i przekształcone w sygnały bocznej i pionowej korekcji położenia uchwytu spawalniczego. Na podstawie sygnałów korygujących, które pobrano bezpośrednio z procesu spawania, uzyskuje się prowadzenie uchwytu w osi rowka w trybie on-line. Bezpośrednie wykorzystanie procesu do prowadzenia uchwytu ma tę zaletę, że w przeciwieństwie do innych sensorów przemysłowych nie wymaga instalowania w otoczeniu uchwytu spawalniczego żadnych dodatkowych urządzeń, często utrudniających dojście uchwytu do złącza. Sensor łukowy można wykorzystywać do wszystkich rodzajów złączy stalowych pod warunkiem, że złącze będzie miało krawędzie o wysokości nie mniejszej niż $5 \mathrm{~mm}$.

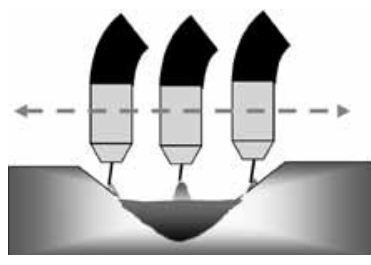

Rys. 4. Zasada funkcjonowania sensora łukowego

Fig. 4. The principle of operation of an arc sensor

\section{Sensory laserowe do pomiarów off-line}

Jedno- lub dwuwymiarowe sensory należą do optymalnych sensorów laserowych pomiaru odległości. Sensory pracują na zasadzie trangulacji, tzn. sensor wysyła punktowy promień laserowy, który odbija się od powierzchni i zostaje przeliczony w odbiorniku głowicy sensorowej (rys. 5). Przy przejeździe sensora nad

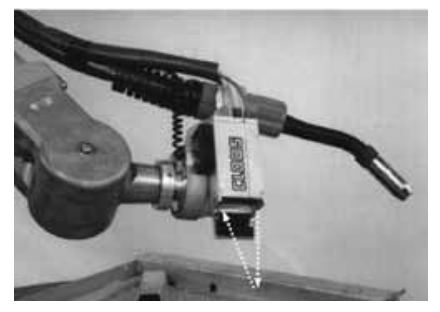

Rys. 5. Laserowy sensor pomiaru odległości

Fig. 5. Laser distance measurement sensor 
powierzchnią detalu zostaje np. rozpoznane złącze zakładkowe, ponieważ na podstawie zmian odległości od głowicy zostaje wytworzony sygnał analogowy sterowania robota, który rozpoznaje miejsce i wielkość uskoku złącza zakładkowego. Ponieważ sensory te pracują bezdotykowo, czynności pomiarowe wykonywane są wielokrotnie szybciej niż przy zastosowaniu sensorów taktylnych.

\section{Sensory laserowe do pomiarów on-line}

Obok sensorów odległości sensor laserowy on-line jest narzędziem uniwersalnym. Przy jego zastosowaniu można wykonać pomiar rowka spawalniczego przed spawaniem oraz w czasie spawania w trybie on-line, dokonując pomiaru rowka przez umieszczenie sensora przed uchwytem spawalniczym, oraz wykorzystać wyniki pomiarów do spawania adaptacyjnego (rys. 6). Sensor laserowy on-line wysyła promień laserowy pod ustalonym kątem. Światłoczuły element sensora przyjmuje promienie odbite od powierzchni wyrobu. Punkt wejścia na optyce odbiorowej daje informację o odległości i pozycji od powierzchni wyrobu, a także informację o geometrii rowka. Te informacje zostają sprawdzone (porównane) na zgodność ze wcześniej zdefiniowanym wzorem. We wzorcu jest dokładnie opisany kształt spoiny łącznie z dopuszczalnymi tolerancjami. Jeśli odchyłki są przekroczone, proces spawania zostaje automatycznie przerwany, aby wyeliminować błędy spawalnicze wynikające z przekroczenia tolerancji. W obszarze ustalonych granic procesu spawania, tzn. prędkości spawania, amplitudy zukosowania, wydajności spawania, zostaną dopasowane do odczytanej geometrii rowka spawalniczego. Dzięki niewielkim wymiarom sensor można umieszczać w pobliżu miejsca spawania i dzięki temu uzyskiwać optymalne warunki do śledzenia przebiegu spoiny. Do integracji sensora z robotem można wykorzystać różne rodzaje interfejsów.

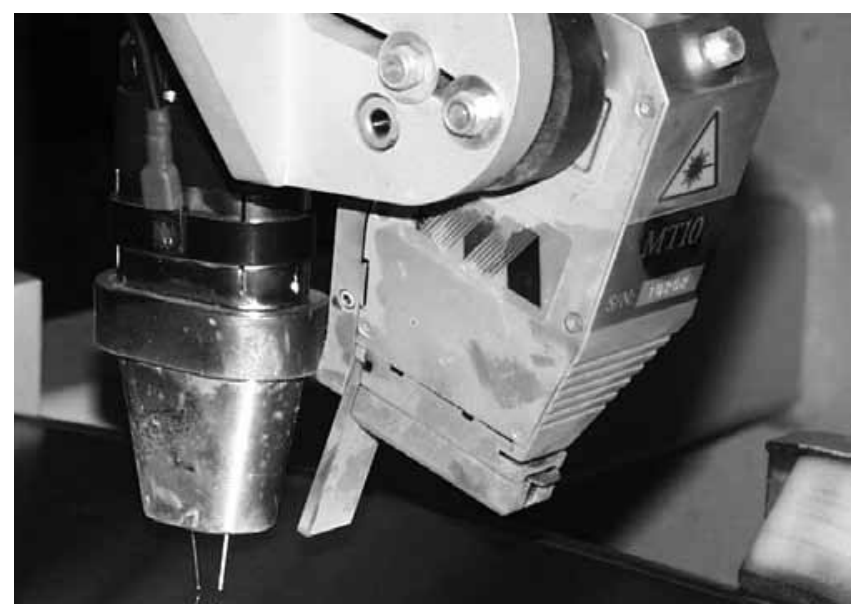

Rys. 6. Sensor laserowy do pomiaru off-line

Fig. 6. Laser sensor for off-line measurements

\section{Transmisja danych surowych}

Sensor wysyła aktualne dane sensora bez dalszej obróbki do nadrzędnego sterowania robota. Sterowanie nadrzędne przejmuje filtrowanie danych sensora i aplikuje je jako korekty TCP w czasie rzeczywistym. Ta metoda ma tę zaletę, że system sensora nie musi być poinformowany o aktualnej pozycji i prędkości TCP.

\section{Transmisja korekt TCP}

Niektóre interfejsy wymagają korekty danych sensora względem TCP dotyczących układu współrzędnych bazowych lub narzędzia. Przy ustawieniu system sensora wymaga wstępnych danych w zakresie aktualnego położenia i prędkości w czasie rzeczywistym, a następnie wymagane są również dane o zorientowaniu narzędzia. System sensora przejmuje wszystkie opracowania danych i analizy.

Przesłane dane są przekazywane do sterowania po przefiltrowaniu.

\section{Koncepcja master}

Są to systemy sensorów, które mierzą w układzie 6D dane położenia oraz dane zorientowania i przejmują kontrolę nad robotem (manipulatorem) prowadząc narzędzie wzdłuż rowka w czasie rzeczywistym.

Śledzenie rowka przez sensor laserowy jest zawsze niezbędne wtedy, kiedy robot spawalniczy jest konfrontowany z częściami obarczonymi tolerancjami, których nie można wykryć za pomocą innych sensorów. Ograniczeniami w stosowaniu sensorów są np. zakresy cienkich blach, spoiny pachwinowe o krawędzi mniejszej niż $5 \mathrm{~mm}$, spoiny czołowe typu I oraz w przypadku sensora łukowego spawanie stopów aluminium. Podczas śledzenia przebiegu spawania sensor pozycjonowany znajduje się we wstępnym

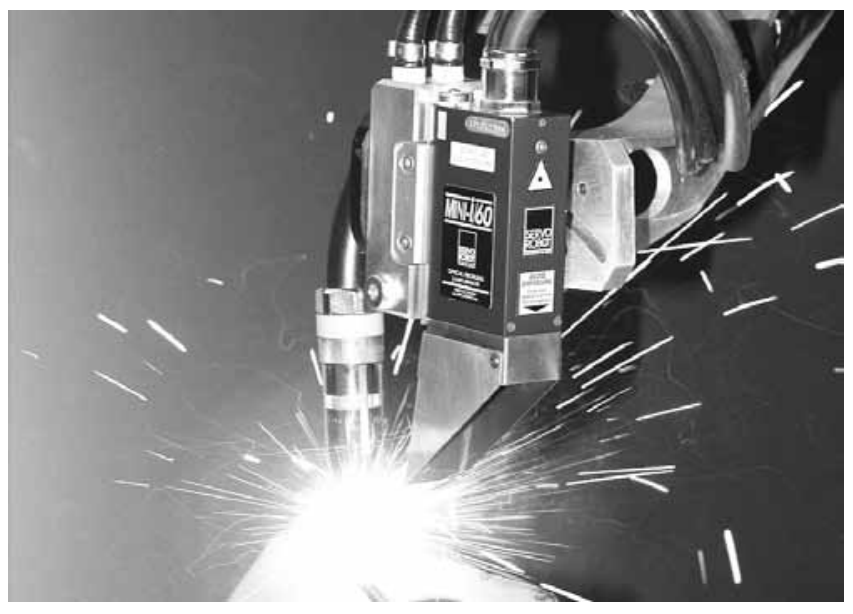

Rys. 7. Sensor laserowy do śledzenia on-line

Fig. 7. Laser sensor for on-line joints follow-up 


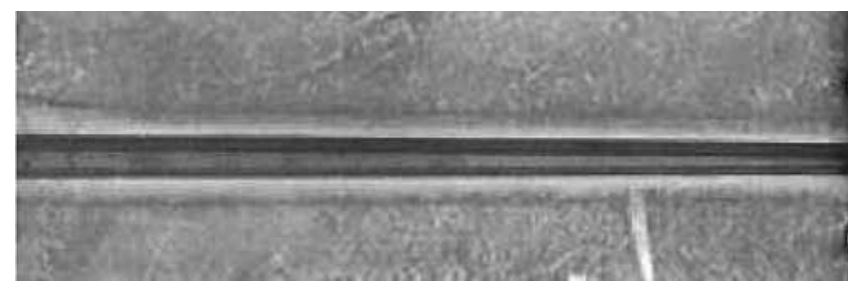

Rys. 8. Przygotowanie złącza

Fig. 8. Preparing the joints

punkcie spoiny, a później przejeżdża w określonym kierunku ze zdefiniowaną prędkością. Po rozpoznaniu geometrii rowka uchwyt spawalniczy zostaje ustawiony na początku spoiny, proces spawania zostaje włączony i uchwyt spawalniczy prowadzony jest wzdłuż rowka. Zakończenie spoiny jest rozpoznawane przez sensor, a dane z rozpoznania zapewniaja zakończenie procesu spawania w rzeczywistym zakończeniu spoiny. Dzięki śledzeniu w trybie on-line zostają rozpoznane tolerancje wykonania wyrobu oraz odkształcenia spawalnicze powstałe w czasie spawania. Dystans pomiędzy promieniem lasera a uchwytem spawalniczym jest uwzględniony przy obliczeniu położenia tak, że uzyskuje się dokładne prowadzenie uchwytu spawalniczego. Rozpoznanie spoiny przez system sensora nie zależy od materiału spawanego i od przygotowania rowka. Ponieważ sensor może pracować $w$ trybie on-line w czasie procesu spawalniczego, jego zastosowanie nie wpływa na czas taktu pracy (rys. 7).

\section{Adaptacja parametrów spawania}

Sensory laserowe 2D dostarczają informacji nie tylko o położeniu, ale również o geometrii rowka. Na podstawie mierzonych wartości można sformułować wnioski o szerokości szczeliny, głębokości rowka i przekroju spoiny, co umożliwia adaptacyjne dopasowanie parametrów spawania (rys. 8). W tych warunkach podczas

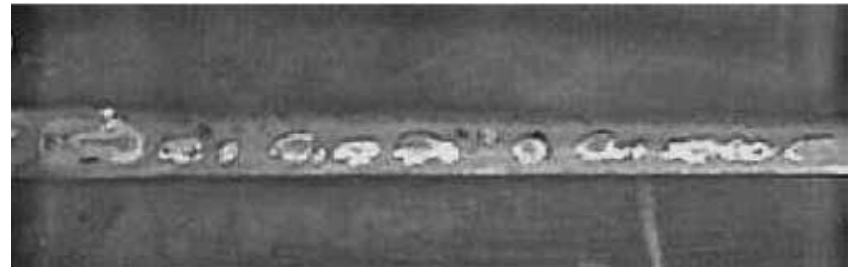

Rys. 9. Złącze pospawane adaptacyjnie

Fig. 9. Adaptively welded joint

procesu spawania $w$ trybie on-line przy zmieniających się wymiarach jeziorka zachodzi proporcjonalne dopasowanie wszystkich niezbędnych parametrów w celu zabezpieczenia optymalnego równomiernego wyglądu spoiny (rys. 9). Przy dopasowywaniu parametrów spawania zachodzi możliwość przełączenia pomiędzy poszczególnymi zestawami parametrów oraz dokonywania analogowo w sposób linearny lub skokowy zmian wszystkich niezbędnych parametrów wynikających z geometrii złącza.

\section{Czynności kontrolne dla zastosowań CAQ}

Sensory laserowe znajdują również zastosowanie w CAQ (Computer Aided Quality Assurance). Są stosowane podczas kontroli spoin $w$ ramach zabezpieczenia jakości. Dla kontrolowanych kryteriów powierzchni złącza zostają opracowane wzorce w zakresie szerokości spoiny, wysokości lica, wycieków grani i porów powierzchniowych. Po zeskanowaniu geometrii spoiny można rozpoznać w mikrometrach zmiany na powierzchni spoiny. Odchyłki niemieszczące się w tolerancji wzorca zostają uznane za niezgodności i są dokumentowane. Poprzez połączenia sieciowe z zakładowym systemem jakości można zapewnić obowiązek dokumentowania przebiegu procesu i jego nadzoru.

\section{Podsumowanie}

Aby stosowanie sensorów stało się bardziej uniwersalne, obok wzrostu sprawności niezbędne jest zmniejszenie wymiarów i stosowanie rozwiązań kompaktowych. Do tego potrzebne jest zwiększenie pola widzenia sensora w celu poprawienia obszaru dojścia oraz zmniejszenie czułości na refleksy powstałe przy odbiciu promienia od

powierzchni. Trójwymiarowe rozpoznanie geometrii szwu i spawanego wyrobu za pomocą systemu sensorowego umożliwi rozwiązywanie dalszych zadań w spawaniu. Zastosowanie sensora trójwymiarowego uczyniłoby $w$ robotyzacji proces rozpoznawania porównywalnym z procesem rozpoznawania przez ludzkie oko. 